www.jmscr.igmpublication.org

Impact Factor 5.244

Index Copernicus Value: 83.27

ISSN (e)-2347-176x ISSN (p) 2455-0450

crossref DOI: _https://dx.doi.org/10.18535/jmscr/v4i10.108

Journal Of Medical Science And Clinical Research

\title{
Case Report: Acute Chordae Tendineae Rupture and Mitral Regurgitation in Pregnancy
}

\author{
Authors: \\ Dr Sachin Ajit Kumar Adukia ${ }^{1}$, Dr Arundhati Girish Diwan, \\ Dr Chandrakant Chavan ${ }^{3}$ \\ ${ }^{1}$ Senior Resident, ${ }^{2}$ Professor and Head, Department of Medicine, ${ }^{3}$ Cardiologist \\ Bharati Vidyapeeth University Medical College and Bharati Hospital, Pune 411043 \\ Corresponding Author \\ Dr Sachin Adukia \\ Email-dr.sachinadukia@gmail.com
}

\begin{abstract}
A 29 year old woman complained of breathlessness, chest pain and palpitations at 36 weeks of gestation. A pansystolic murmur alongwith bilateral basal crepitations were heard on auscultation. Echocardiography revealed a thickened anterior mitral leaflet with doming and a fixed posterior mitral leaflet. It also revealed chordae tendineae rupture. These findings were consistent with the diagnosis of acute heart failure due to ruptured chordae tendineae. An elective caesarean section was performed under general anaesthesia and a female child of $1.67 \mathrm{kgs}$ was born. The patient subsequently recovered and was discharged. Though acute heart failure in pregnancy may be life threatening, proper diagnosis and treatment in the ICU can assure a good outcome.
\end{abstract}

KEYWORDS:- Acute LVF, mitral valve edema.

\section{INTRODUCTION}

Most cases of chordae tendineae rupture are because of degeneration leading to thickening and retraction of valve leaflets. Rarely, it can occur due to endocarditis, either acutely, or later, if fibrosis develops and distorts the chordae. In case of a floppy mitral valve, when it prolapses, it may pull on the chordae hard enough to tear them. The important etiological factors for rupture of chordae tendineae are bacterial endocarditis, rheumatic valvular disease and trauma. Other causes include congenital heart disease, Marfan's syndrome, Ehler-Danlos syndrome, hypertrophic obstructive cardiomyopathy, ischemic heart disease, previous surgery, blunt trauma and idiopathic. Mitral valve regurgitation, even when severe, is usually well tolerated in pregnancy as the increased volume overload on the left ventricle is balanced by a decrease in total peripheral resistance. But, patients with even moderate pulmonary hypertension or dyspnoea (New York heart association Class III or IV) are at high risk of heart failure and arrhythmias. We are reporting a case of chordal rupture leading to mitral regurgitation and acute left heart failure probably due to pregnancy itself. 


\section{CASE REPORT}

A 29 year old female $\left(\mathrm{G}_{4} \mathrm{P}_{3} \mathrm{~L}_{1} \mathrm{~A}_{0}\right)$ presented at 36 weeks of gestation, with complaints of breathlessness since three days which had increased since 6 hours. It was accompanied by chest discomfort and palpitations since 6 hours. She did not have fever, cough with expectoration, calf tenderness. She had history of pregnancy induced hypertension, Possibilities like pulmonary embolism, peripartum cardiomyopathy, severe lower respiratory tract infection and acute mitral regurgitation were considered. On examination patient was afebrile, with a pulse of 126 beats per minute, blood pressure of $120 / 80 \mathrm{~mm}$ of $\mathrm{Hg}$, respiratory rate of 28 per minute and an oxygen saturation of $92 \%$ on room air. She had a raised jugular venous pressure, mild pedal oedema and no calf tenderness. Cardiovascular auscultation revealed evidence of mitral regurgitation a pansystolic, high pitched murmur (Grade IV/VI), best heard over the apex, radiating posteriorly to the interscapular region and loudest in expiration. No diastolic murmurs were appreciated. Bilateral basal crepitations were present with no absent air entry. Rest of the examination was normal. ECG revealed a sinus tachycardia with no evidence of ischemia or chamber enlargement. Chest x-ray with lead shield showed bilateral mid and basal haziness and congestion. Echocardiography revealed thickened anterior mitral leaflet (AML) with doming and paradoxical motion (Figure 1).

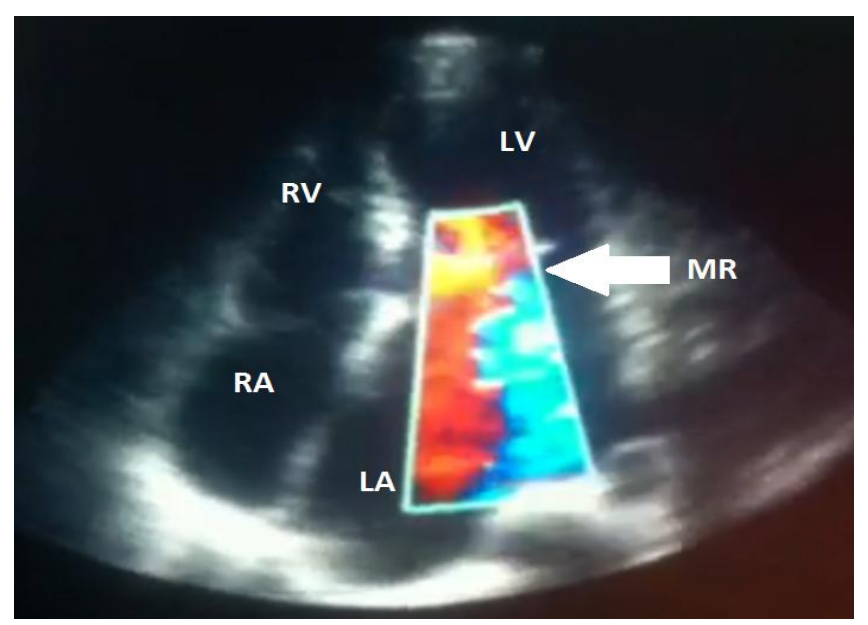

"Figure 1: 2D echocardiography with Colour Doppler showing severe Mitral Regurgitation
(White Arrow); MR-mitral regurgitation, LA-Left atrium, LV-left Ventricle, RA-Right Atrium, RVRight Ventricle."

The posterior mitral leaflet (PML) was relatively fixed. Also seen were minor chordal rupture with severe mitral regurgitation (grade 4/4) and moderate tricuspid regurgitation (2/4). The left ventricle, left atrium and right atrium were dilated. There was no evidence of rheumatic affliction of the mitral valve apparatus. She also had severe pulmonary hypertension (right ventricular systolic pressure $70 \mathrm{mmHg}$ ). Serum brain natriuretic peptide level was 600 pictograms $/ \mathrm{ml}$ (normal= 0 to 100 pictograms $/ \mathrm{ml}$ ) favouring acute heart failure. All other blood investigations were normal. Investigations for systemic vasculitis did not offer any positive results. Blood and induced sputum were sent for culture and sensitivity, which yielded no growth. Ultrasound examination of the abdomen and pelvis revealed a single live intrauterine foetus with oligohydramnios but was otherwise was within normal limits. She was started on diuretics and antibiotics and was given non-invasive ventilatory support. An elective caesarean section was done on the fourth day of admission and was uneventful. The patient's symptoms subsided using diuretics and the oxygen supplementation was gradually withdrawn. She was subsequently discharged by day 10 of admission. She was advised to undergo further evaluation to plan surgical repair of the mitral valve but she was lost to follow up.

\section{DISCUSSION}

Of the available literature on chordal rupture associated with pregnancy, infective endocarditis was present in some. ${ }^{[4,5,6]}$ while in others, no specific aetiology other than pregnancy and labour was identified. ${ }^{[1,2,3]}$ Hormonal changes in pregnancy might be responsible for chordal rupture, and also softening of the mitral leaflets as well as the mitral annulus. Additionally, the increase in cardiac output in pregnancy might contribute to the crisis. Diagnosis should be based on the following clinical findings: 1 . Sudden onset 
and rapid progression of dyspnoea and fatigue in a previously healthy patient 2 . Findings of severe $\mathrm{MR}$, i.e. a systolic thrill, a widely radiating pan systolic murmur and pulmonary hypertension 3 . Sinus rhythm 4.Minimal enlargement of the left atrium. Our patient met all four criteria listed above.

Treatment should proceed on the lines of acute left ventricular failure and pulmonary oedema if present. Diuretics and oxygen supplementation remain the cornerstone of therapy. Surgical treatment should be considered in the appropriate clinical setting. Prostheses like bovine pericardium premoulded chordae may be used. Annuloplasty may be performed using prosthetic ring like the Gregori-Braile prosthetic ring. Other techniques include chordal shortening, leaflet resection or leaflet enlargement of the PML using a bovine pericardial patch. ${ }^{[8]}$

\section{REFERENCES}

1. Caves PK, Paneth M. Acute MR in pregnancy due to ruptured chordae tendineae. Br Heart J 1972; 34: 541-544.

2. Nakash A, Arafa A, Vrapi F, Zaid R. An unusual case of peripartum ruptured mitral valve. Jr Obstetric Gynaecology 2009; 29:768-76.

3. SugikoOhishi, Hyase Nitta, Yukiko Chinen et al. Acute congestive heart failure due to ruptured mitral chordate tendineae in late pregnancy. J. Obstetric Gynaecology. Res 2013; 39(3):724-726.

4. Olivera DB, Dawkins KD, Kay PH, Paneth M. Chordal rupture. I: Aetiology and natural history. Br Heart J 1983; 50:312317.

5. Castillo RA, Llado I, Adamsons K. Ruptured chordaltendineae complicating pregnancy. A case report. J. Reproductive medicine 1987; 32:137-39.

6. Hagway ZJ, Weissman A, Geva D, Snir E, Capsi A. Labor and delivery complicated by acute mitral regurgitation due to ruptured chordate tendineae. Am J. Perinatology 1995; 12:111-12

7. Raffery EB, Oakley CM, Goodwin JF. Acute subvalvular mitral incompetence. Lancet 1966; 360-365.

8. Gregori Junior, Francisco et al. Surgical repair of chordae tendineae rupture after degenerative valvular regurgitation using standardized bovine pericardium. Rev Bras Cir Cardiovasc [online]. 2013, vol.28, n.1 [cited 2013-07-05], pp. 36-46 . Available from:<http://www.scielo.br/scielo.php?scri pt=sci_arttext\&pid=S0102- 76382013000100007\&lng=en\&nrm=iso $>$.ISSN01027638. http://dx.doi.org/10.5935/16789741.20130007 